\title{
Comparison of Mortality Risk Models in Patients with Postcardiac Arrest Cardiogenic Shock and Percutaneous Mechanical Circulatory Support
}

\author{
Georgios Chatzis $\mathbb{D}^{D}$, Birgit Markus $\mathbb{D}^{D}$, Styliani Syntila $\mathbb{D}^{D}$, Christian Waechter $\mathbb{D}^{D}$, \\ Ulrich Luesebrink $\left(\mathbb{D}\right.$, Holger Ahrens $\left(\mathbb{D}\right.$, Dimitar Divchev $\mathbb{D}^{D}$, Bernhard Schieffer $(\mathbb{D}$, \\ and Konstantinos Karatolios
}

Department of Cardiology, Angiology and Intensive Care, Philipps University Marburg, Marburg, Germany

Correspondence should be addressed to Georgios Chatzis; chatzis@staff.uni-marburg.de

Received 1 September 2020; Revised 20 December 2020; Accepted 30 December 2020; Published 18 January 2021

Academic Editor: Martin J. Swaans

Copyright (c) 2021 Georgios Chatzis et al. This is an open access article distributed under the Creative Commons Attribution License, which permits unrestricted use, distribution, and reproduction in any medium, provided the original work is properly cited.

\begin{abstract}
Background. Although scoring systems are widely used to predict outcomes in postcardiac arrest cardiogenic shock (CS) after outof-hospital cardiac arrest (OHCA) complicating acute myocardial infarction (AMI), data concerning the accuracy of these scores to predict mortality of patients treated with Impella in this setting are lacking. Thus, we aimed to evaluate as well as to compare the prognostic accuracy of acute physiology and chronic health II (APACHE II), simplified acute physiology score II (SAPS II), sepsisrelated organ failure assessment (SOFA), the intra-aortic balloon pump (IABP), CardShock, the prediction of cardiogenic shock outcome for AMI patients salvaged by VA-ECMO (ENCOURAGE), and the survival after venoarterial extracorporeal membrane oxygenation (SAVE) score in patients with OHCA refractory CS due to an AMI treated with Impella 2.5 or CP. Methods. Retrospective study of 65 consecutive Impella 2.5 and 32 CP patients treated in our cardiac arrest center from September 2015 until June 2020. Results. Overall survival to discharge was $44.3 \%$. The expected mortality according to scores was SOFA 70\%, SAPS II $90 \%$, IABP shock 55\%, CardShock 80\%, APACHE II 85\%, ENCOURAGE 50\%, and SAVE score $70 \%$ in the 2.5 group; SOFA $70 \%$, SAPS II $85 \%$, IABP shock 55\%, CardShock $80 \%$, APACHE II $85 \%$, ENCOURAGE $75 \%$, and SAVE score $70 \%$ in the CP group. The ENCOURAGE score was the most effective predictive model of mortality outcome presenting a moderate area under the curve (AUC) of 0.79, followed by the CardShock, APACHE II, IABP, and SAPS score. These derived an AUC between 0.71 and 0.78. The SOFA and the SAVE scores failed to predict the outcome in this particular setting of refractory CS after OHCA due to an AMI. Conclusion. The available intensive care and newly developed CS scores offered only a moderate prognostic accuracy for outcomes in OHCA patients with refractory CS due to an AMI treated with Impella. A new score is needed in order to guide the therapy in these patients.
\end{abstract}

\section{Introduction}

Postcardiac arrest cardiogenic shock (CS) after out-of-hospital cardiac arrest (OHCA) complicating acute myocardial infarction (AMI) remains associated with a very poor prognosis, despite improvements in prehospital management and progress of postresuscitation care [1-3]. Ventricular failure subsequent to AMI remains the most frequent cause of cardiogenic shock (CS) accounting for more than $80 \%$ of cases [4]. In addition to inotropes, vasopressors, and revascularization of the infarct-related coronary artery, percutaneous left ventricular assist devices are used to support the circulation and improve the cardiac output and end-organ perfusion in these patients [5-7]. In a previous retrospective investigation, hemodynamic support with Impella was associated with improved survival compared to medical treatment in patients with postcardiac arrest CS related to AMI [8]. However, little is known about the management of patients treated with Impella in terms of survival prediction or survival with good neurological outcome. The most 
available scoring systems for survival after intensive care unit (ICU) admission, such as Acute Physiology and Chronic Health Score II (APACHE II), Simplified Acute Physiology Score II (SAPS II), and the sepsis-related organ failure assessment score (SOFA) have been used only sparsely in previous studies. However, none of them showed effective predictive value in patients with CS, especially in patients treated with percutaneous assist devices, such as the intraaortic balloon pump (IABP) or Impella [9-12]. The IABP score is based on six parameters and was created in terms of the IABP Shock Trial to predict mortality in patients with CS undergoing support with IABP [13], while the CardShock score is also a relative newly developed score to predict outcomes in patients with heart failure [14]. These scores have been recently shown to be good predictors of in-hospital mortality in patients with CS; however, little is known about their predictive value in patients treated with Impella $[12,15,16]$. The prediction of cardiogenic shock outcome for AMI patients salvaged by VA-ECMO score (ENCOURAGE) and the survival after venoarterial extracorporeal membrane oxygenation (ECLS) score (SAVE) were originally developed for ECLS patients; there are only few studies that arranged the predictive value of these scores in patients treated exclusively with Impella [17-19].

In the same direction, the use of Impella in patients with severe CS is often related with adverse events and complications, demanding special training and resources. Therefore, more than ever, a reliable prediction model is needed in order to predefine which patients would benefit from the implantation of such a device. The patients with postcardiac arrest CS comprise a group of very ill patients with even worse outcome compared to patients without cardiac arrest. The implementation of predictive scores in these patients is a special challenge in the field of intensive care and cardiology. Since no study so far has focused on the predictive capacity of the aforementioned scores in postcardiac arrest patients due to an AMI treated with Impella, we aimed to study and compare the predictive accuracy of these scores in this setting of patients.

\section{Methods}

2.1. Patients' Characteristics. We retrospectively analyzed data from all patients resuscitated from OHCA due to AMI with postcardiac arrest CS who were supported with Impella 2.5 from September 2015 to June 2020. For this purpose, we reviewed our Impella registry to identify all OHCA patients admitted within this period to our institution who received Impella 2.5 or Impella CP support for postcardiac arrest CS complicating an AMI. All study patients underwent percutaneous coronary intervention (PCI). Patients with refractory OHCA under cardiopulmonary resuscitation on admission and patients with OHCA due to other causes were excluded from the analysis. Postcardiac arrest CS was defined as the need for continuous infusion of vasopressors to maintain systolic blood pressure $>90 \mathrm{mmHg}$ after return of spontaneous circulation. Timing of Impella implantation (pre- or post-PCI) was at the operating physician's discretion. Intention of therapy in cardiogenic shock was the use of Impella CP; however, Impella 2.5 was placed upon unavailability of this device. Coronary angiography and PCI were performed in a conventional manner. Patients were treated with drug-eluting stents and/or percutaneous transluminal coronary angioplasty. The extent of coronary revascularization and adjunctive therapies were left at the operator's discretion.

A subset $(n=27)$ of the Impella patients has been previously published [8]. The study was approved by the local ethics committee of the Philipps University of Marburg. The need for informed consent was waived due to the retrospective nature of the study. The study adheres to the STROBE guidelines for observational studies.

2.2. Device Management. All Impella devices were implanted through the femoral artery and placed via the retrograde approach through the aortic valve into the left ventricle under fluoroscopic control in the catheterization laboratory. All OHCA patients were treated with targeted temperature management (mild hypothermia of $33-34^{\circ} \mathrm{C}$ ) for $24 \mathrm{~h}$ with an endovascular cooling device (Thermogard XP Temperature Management System, Zoll Medical Corporation, USA). After $24 \mathrm{~h}$, gradual rewarming to $37^{\circ} \mathrm{C}$ in an hourly increment of $0.25^{\circ} \mathrm{C}$ was commenced in all patients. The intention was to maintain a body temperature below or equal to $37^{\circ} \mathrm{C}$ until $72 \mathrm{~h}$ after cardiac arrest. Inotropes and vasopressors were used to obtain a mean arterial pressure $\geq 65 \mathrm{mmHg}$. In patients with Impella support, flow was adjusted to maintain mean arterial pressure $\geq 65 \mathrm{mmHg}$ with the lowest possible dose of catecholamines and to cover metabolic needs as assessed by central venous oxygen saturation $(\geq 70 \%)$ and serum lactate levels $(<2.0 \mathrm{mmol} / \mathrm{L})$. A standardized protocol for the management of kidney function and the indication for renal replacement therapy was used. The decision to wean the circulatory support device was based on the resolution of shock and clinical assessment. Weaning process was performed by gradually decreasing Impella support. Once the support of the device was reduced to low levels (performance level 1) with stable mean arterial pressure $\geq 65 \mathrm{mmHg}$, no or low doses of catecholamines, central venous oxygen saturation $\geq 70 \%$, and serum lactate levels $<2.0 \mathrm{mmol} / \mathrm{L}$, the device was removed in ICU, and hemostasis was achieved with a mechanical compression tool (FemoStop, Abbott Laboratories).

2.3. Data Collection and Study Endpoints. Intrahospital clinical data, outcomes, and follow-up data were collected from the medical charts. Prehospital arrest data were collected with the use of a preformatted standard data collection tool, including witnessed arrest, bystander CPR, no-flow time, duration of CPR, shockable or nonshockable rhythm, number of shocks, and epinephrine dosage during CPR.

The primary endpoint of our study was to assess the survival rates between patients supported with Impella 2.5 and CP as well as to compare the predictive value of SAPS II, SOFA, APACHE II, IABP shock, CardShock, ENCOURAGE, and SAVE score in these patients' collectives. Complication rates are also reported. Complications included 
bleeding at the insertion site, limb ischemia, and vascular complications requiring surgical or interventional repair. Bleeding was defined as blood loss at the Impella insertion site requiring blood transfusion, whereas other bleeding was defined as any bleeding irrespective of Impella use. Limb ischemia was defined as clinical hypoperfusion of the leg (decreased skin temperature of the leg and/or decreased peripheral pulses) requiring treatment or extraction of the device. Vascular complications requiring surgical or percutaneous repair were defined as intervention (surgical or percutaneous) on a vessel dissection, a pseudoaneurysm, an access-site thrombosis, or an arteriovenous fistula. Cerebral functional status was determined according to the Pittsburgh cerebral performance category (CPC) based on medical records or discharge summary abstracts.

2.4. Statistical Analysis. All data were analyzed retrospectively. Data are presented as absolute variables and percentages (\%) for categorical variables and either median with interquartile range (IQR: $25^{\text {th }}-75^{\text {th }}$ percentile) or mean with standard deviation according to the distribution of the variables. We assessed normality using Shapiro-Wilk test as well as Pearson test. After testing for normal distribution, Student's $t$-test or Mann-Whitney test was implemented to test for differences between various characteristics. For categorical variables, Fisher's exact test or chi-square test was used, as appropriate. In order to compare the predictive value of different scores, we calculated the area under the curve of each score.

All analyses were made using SPSS 24 (IBM Corp., USA) and GraphPad Prism 6.0. A two-sided $p$ value $<0.05$ was considered statistically significant.

\section{Results}

From September 2015 to June 2020, a total of 97 consecutive patients who had postcardiac arrest CS related to AMI and underwent Impella implantation for left ventricle (LV) mechanical assistance and PCI were included in the present retrospective analysis. The 2.5 group consisted of 65 patients, whereas the group of $\mathrm{CP}$ consisted of 32 patients. The mean age of our Impella 2.5 cohort was $67.86 \pm 12.82$ years and of our Impella CP was $66 \pm 13.92$ years, with survivors being significantly younger $(p<0.001$ in both groups), while $84.6 \%(55 / 65)$ in Impella 2.5 and $63 \%$ (20/32) in Impella CP were male without any difference in the distribution among survivors or nonsurvivors. All patients sustained an OHCA prior to admission, all patients were on mechanical ventilation, and all patients were in CS with need of catecholamines at the time of admission. On admission, median baseline systolic left ventricular ejection fraction (LVEF) was $32.19 \% \pm 7.32 \%$ in the Impella 2.5 group showing no difference between survivors and nonsurvivors, whereas in the Impella CP group, the median LVEF was $31.07 \% \pm 7.35 \%$, showing a statistically significant difference between survivors and nonsurvivors. As expected, the age-adjusted Charlson comorbidity index was significantly lower among survivors in both groups, mainly driven by age and better kidney function. The nonsurvivors had a significantly worse cardiac arrest profile with longer periods of no-flow time, higher need for noradrenaline, and higher levels of renal clearance markers and serum lactate upon admission. In the group of Impella $2.5,28(43.1 \%)$ patients suffered from rib fractures and $14(21.5 \%)$ from pneumothoraces that were successfully drained. In the Impella CP group, 14 patients $(43.8 \%)$ were diagnosed with rib fractures upon admission, and 5 of them (14.7\%) needed a pleural drainage for the pneumothorax. None of the traumatic injuries demanded further operative treatments. The baseline characteristics of the study population are listed in Table 1.

The device was successfully implanted through transfemoral access in all patients, while in 2 patients in the Impella 2.5 group, the PCI was not successful, one in the survivor group and one in the nonsurvivor group $(p=1)$. A far as the procedural characteristics are concerned, there were no differences in the delays to hospital transfer or to balloon implantation (door to balloon) from the admission to the hospital. The duration of intervention and the amount of the contrast agent used were similar in both groups. The delay to Impella support was significantly lower among survivors in both groups compared to nonsurvivors ( $p=0.02$ in 2.5 and $p=0.03$ in the CP group). In $14(21.5 \%)$ patients of Impella 2.5 and in 9 (28.1\%) patients of Impella $\mathrm{CP}$, a multivessel intervention was successfully undertaken (no differences between the survivors and nonsurvivors in both groups). The extent of coronary artery disease was similar in both groups, and the culprit vessel was predominantly the left anterior descending artery. All procedural characteristics of the study population are demonstrated in Table 2.

The overall survival to hospital discharge in the entire cohort was $44.3 \%$ (43/97) (Table 3). The main cause of death was refractory CS occurring in $91.7 \%$ in the 2.5 group and in $83.3 \%$ in the CP group. Device-related vascular complications were more frequent among Impella $\mathrm{CP}$ patients (total of $16.9 \%$ and $28.1 \%$ in Impella 2.5 and $\mathrm{CP}$, respectively). Access-site bleeding requiring transfusion occurred in $9.2 \%$ of the Impella 2.5 and in $21.9 \%$ of the Impella CP patients. Limb ischemia requiring extraction of the device and limb ischemia requiring percutaneous or surgical repair were also more frequent among the Impella CP patients. None of our patients experienced an in-hospital myocardial reinfarction, while one of the Impella $\mathrm{CP}$ patients suffered a stroke, leading to CPC 4 upon discharge. Nondevice-related bleeding was observed in 3 patients in the Impella 2.5 group and in 2 patients of Impella CP. All mentioned complication rates were comparable between the two study groups. The survival and safety outcomes are listed in Table 3.

On admission, all ICU and CS scores were significantly higher in the group of the nonsurvivors (except for SOFA in the Impella CP group). According to the scores calculated on admission, it can be assumed that this patient group was critically ill; the expected mortality among Impella 2.5 patients according to SOFA, SAPS, IABP shock, CardShock, APACHE II, ENCOURAGE, and SAVE score was 70\%, 90\%, $55 \%, 80 \%, 85 \%, 50 \%$, and $70 \%$, respectively. Accordingly, the expected mortality of the Impella CP patients based on 
TABle 1: Demographics and baseline characteristics of the study population.

\begin{tabular}{|c|c|c|c|c|c|c|c|c|}
\hline & $\begin{array}{l}\text { Impella } 2.5 \\
(N=65)\end{array}$ & $\begin{array}{l}\text { Survivors } \\
(N=29)\end{array}$ & $\begin{array}{l}\text { Nonsurvivors } \\
\quad(N=36)\end{array}$ & $\begin{array}{c}p \\
\text { value }\end{array}$ & $\begin{array}{c}\text { Impella CP } \\
(N=32)\end{array}$ & $\begin{array}{c}\text { Survivors } \\
(N=14)\end{array}$ & $\begin{array}{l}\text { Nonsurvivors } \\
\quad(N=18)\end{array}$ & $\begin{array}{c}p \\
\text { value }\end{array}$ \\
\hline Age, years & $67.86 \pm 12.82$ & $59.90 \pm 12.23$ & $74.28 \pm 9.29$ & $<0.001$ & $66 \pm 13.92$ & $55.43 \pm 13.30$ & $74.22 \pm 7.39$ & $<0.001$ \\
\hline Gender, male/female & $55 / 10$ & $25 / 4$ & $30 / 6$ & 1 & $20 / 12$ & $10 / 4$ & $10 / 8$ & 0.47 \\
\hline BMI, $\mathrm{kg} / \mathrm{m}^{2}$ & $27.60 \pm 3.63$ & $26.63 \pm 2.91$ & $28.35 \pm 3.98$ & 0.06 & $29.01 \pm 3.33$ & $27.37 \pm 2.96$ & $30.28 \pm 3.09$ & 0.01 \\
\hline \multicolumn{9}{|l|}{ Medical comorbidities } \\
\hline Hypertension, $n(\%)$ & $48(73.8)$ & $19(65.5)$ & $29(80.6)$ & 0.26 & $23(72)$ & $8(57.1)$ & $15(83)$ & 0.13 \\
\hline Diabetes, $n(\%)$ & $21(32.3)$ & $9(31)$ & $12(33.3)$ & 1 & $16(50)$ & $6(42.9)$ & $10(55.6)$ & 0.72 \\
\hline $\mathrm{PAD}, n(\%)$ & $21(32.3)$ & $8(27.6)$ & $13(36.1)$ & 0.6 & $11(34)$ & $6(42.9)$ & $5(27.8)$ & 0.47 \\
\hline Stroke, $n(\%)$ & $5(7.7)$ & $1(3.3)$ & $4(11.1)$ & 0.37 & $3(9.4)$ & $0(0)$ & $3(16.7)$ & 0.53 \\
\hline $\mathrm{COPD}, n(\%)$ & $12(18.5)$ & $4(13.8)$ & $8(22.2)$ & 0.52 & 7 (21.9) & $2(14.3)$ & $5(27.8)$ & 0.43 \\
\hline $\begin{array}{l}\text { Renal insufficiency } \\
\text { (GFR }<60 \mathrm{ml} / \mathrm{min}), n \\
(\%)\end{array}$ & $44(67.7)$ & $14(48.3)$ & $30(83.3)$ & 0.004 & $26(81.3)$ & $11(78.6)$ & $15(83.3)$ & 1 \\
\hline Prior CAD, $n(\%)$ & $26(40)$ & $10(34.5)$ & $16(44.4)$ & 0.45 & $7(21.9)$ & $4(28.6)$ & $3(16.7)$ & 0.67 \\
\hline Prior MI, $n(\%)$ & $23(35.4)$ & $9(31)$ & $12(33.3)$ & 1 & $5(15.6)$ & $2(14.3)$ & $3(16.7)$ & 1 \\
\hline Prior PCI, $n(\%)$ & $22(33.8)$ & $9(31)$ & $13(36.1)$ & 0.79 & $2(6.3)$ & $2(14.3)$ & $0(0)$ & 0.18 \\
\hline Prior CABG, $n(\%)$ & $9(13.8)$ & $3(10.3)$ & $6(16.7)$ & 0.72 & $2(6.3)$ & $2(14.3)$ & $0(0)$ & 0.18 \\
\hline $\begin{array}{l}\text { Charlson comorbidity } \\
\text { index (age-adjusted) }\end{array}$ & $4.42 \pm 2.93$ & $2.64 \pm 1.81$ & $5.81 \pm 2.9$ & $<0.001$ & $4.03 \pm 2.82$ & $2.86 \pm 2.18$ & $4.94 \pm 2.98$ & $<0.001$ \\
\hline \multicolumn{9}{|l|}{ Cardiac arrest variables } \\
\hline $\begin{array}{l}\text { Witnessed arrest, } n \\
(\%)\end{array}$ & $47(72.3)$ & $21(72.4)$ & $26(72.2)$ & 1 & $20(62.5)$ & $10(71.4)$ & $10(55.6)$ & 0.47 \\
\hline $\begin{array}{l}\text { Shockable rhythm } \\
\text { (VT or VF), } n(\%)\end{array}$ & $42(64.6)$ & $25(86.2)$ & $17(47.2)$ & 0.002 & $19(59.4)$ & $10(71.4)$ & $9(50)$ & 0.29 \\
\hline No-flow time (min) & $4[1.5-7]$ & $2[0-4.5]$ & $6[3-10]$ & 0.0005 & $3.5[2-6]$ & $2[1-4]$ & $4.5[3-10]$ & 0.005 \\
\hline Low-flow time (min) & $24.23 \pm 13.86$ & $19.03 \pm 11.55$ & $28.42 \pm 14.29$ & 0.0057 & $27.94 \pm 15.58$ & $23.71 \pm 10.78$ & $31.22 \pm 18.11$ & 0.18 \\
\hline Bystander CPR, $n(\%)$ & $42(64.6)$ & $21(72.4)$ & $21(58.3)$ & 0.3 & $19(59.4)$ & $10(71.4)$ & $9(50)$ & 0.29 \\
\hline $\begin{array}{l}\text { Number of electric } \\
\text { shocks, median (IQR) }\end{array}$ & $3[1-5]$ & $3[2-6]$ & $2.5[0-4.75]$ & 0.11 & $3 \pm 2.72$ & $4 \pm 2.42$ & $1[0-5]$ & 0.05 \\
\hline $\begin{array}{l}\text { Epinephrine during } \\
\text { resuscitation, } n(\%)\end{array}$ & $58(89.2)$ & $24(82.8)$ & $34(94.4)$ & 0.23 & $32(100)$ & $14(100)$ & $18(100)$ & 1 \\
\hline $\begin{array}{l}\text { Total epinephrine dose } \\
\text { during resuscitation } \\
(\mathrm{mg})\end{array}$ & $4[1.9-6]$ & $2[1-5]$ & $4[2-6.5]$ & 0.06 & $4[3-6]$ & $5[3-6]$ & $4[2.75-6]$ & 0.29 \\
\hline Time till ROSC (min) & $28.71 \pm 14.88$ & $21.76 \pm 11.74$ & $34.31 \pm 14.91$ & 0.0005 & $28[22.5-34]$ & $27[18-28]$ & 33 [28-59] & 0.008 \\
\hline $\begin{array}{l}\text { Traumatic injuries on } \\
\text { admission, } n(\%)\end{array}$ & $30(46.2)$ & $15(51.7)$ & $15(41.7)$ & 0.46 & $14(43.8)$ & $6(42.9)$ & $8(44.4)$ & 1 \\
\hline \multicolumn{9}{|l|}{ Catecholamines } \\
\hline $\begin{array}{l}\text { Inotropes } \\
\text { (dobutamine), } n(\%)\end{array}$ & $51(78.5)$ & $25(86.2)$ & $26(72.2)$ & 0.23 & $24(75)$ & $12(85.7)$ & $12(66.7)$ & 0.41 \\
\hline $\begin{array}{l}\text { Dobutamine }(\mu \mathrm{g} / \mathrm{kg} / \\
\text { min) }\end{array}$ & $4.384[0-6.41]$ & $\begin{array}{c}5.13 \\
{[3.39-6.31]}\end{array}$ & $2.6[0-7.1]$ & 0.1 & $5.42 \pm 1.6$ & $5.4 \pm 1.1$ & $5.46 \pm 2.03$ & 0.97 \\
\hline Norepinephrine, $n(\%)$ & $65(100)$ & $29(100)$ & $36(100)$ & 1 & $32(100)$ & $14(100)$ & $18(100)$ & 1 \\
\hline $\begin{array}{l}\text { Norepinephrine }(\mu \mathrm{g} / \\
\mathrm{kg} / \mathrm{min})\end{array}$ & $0.42 \pm 0.25$ & $0.33 \pm 0.28$ & $0.49 \pm 0.21$ & 0.01 & $0.36 \pm 0.13$ & $0.29 \pm 0.16$ & $0.41 \pm 0.1$ & 0.01 \\
\hline Epinephrine, $n(\%)$ & $13(20)$ & $3(10.3)$ & $10(27.8)$ & 0.12 & $8(25)$ & $4(28.6)$ & $5(27.8)$ & 1 \\
\hline $\begin{array}{l}\text { Epinephrine }(\mu \mathrm{g} / \mathrm{kg} / \\
\min )\end{array}$ & $0.12 \pm 0.04$ & $0.04 \pm 0.03$ & $0.18 \pm 0.07$ & $<0.001$ & $0.65 \pm 0.25$ & $0.52 \pm 0.19$ & $0.76 \pm 0.26$ & 0.17 \\
\hline $\begin{array}{l}\text { Mechanical } \\
\text { ventilation, } n(\%)\end{array}$ & $65(100)$ & $29(100)$ & $36(100)$ & 1 & $32(100)$ & $14(100)$ & $18(100)$ & 1 \\
\hline \multicolumn{9}{|c|}{ Hemodynamic variables on admission } \\
\hline Heart rate $(\mathrm{bpm})$ & $88.27 \pm 22.27$ & $81.43 \pm 20.36$ & $93.58 \pm 22.51$ & 0.03 & $98.31 \pm 17.80$ & $98.29 \pm 19.55$ & $98.33 \pm 16.89$ & 0.99 \\
\hline $\begin{array}{l}\text { Systolic arterial } \\
\text { pressure }(\mathrm{mmHg})\end{array}$ & $97.44 \pm 24.30$ & $100.9 \pm 24.42$ & $94.75 \pm 24.20$ & 0.32 & $98.63 \pm 13.30$ & $93.29 \pm 18.12$ & $102.8 \pm 5.48$ & 0.04 \\
\hline $\begin{array}{l}\text { Diastolic blood } \\
\text { pressure }(\mathrm{mmHg})\end{array}$ & $55.31 \pm 13.71$ & $57.86 \pm 15.66$ & $53.33 \pm 11.83$ & 0.19 & $58.47 \pm 7.74$ & $57.57 \pm 10.65$ & $59.17 \pm 4.62$ & 0.57 \\
\hline $\begin{array}{l}\text { Mean blood pressure } \\
(\mathrm{mmHg})\end{array}$ & $69.35 \pm 16.21$ & $72.20 \pm 17.37$ & $67.14 \pm 15.12$ & 0.22 & $71.85 \pm 8.85$ & $69.48 \pm 12.46$ & $73.70 \pm 3.98$ & 0.18 \\
\hline
\end{tabular}


TABLE 1: Continued.

\begin{tabular}{|c|c|c|c|c|c|c|c|c|}
\hline & $\begin{array}{l}\text { Impella } 2.5 \\
(N=65)\end{array}$ & $\begin{array}{l}\text { Survivors } \\
(N=29)\end{array}$ & $\begin{array}{l}\text { Nonsurvivors } \\
(N=36)\end{array}$ & $\begin{array}{c}p \\
\text { value }\end{array}$ & $\begin{array}{l}\text { Impella CP } \\
(N=32)\end{array}$ & $\begin{array}{l}\text { Survivors } \\
(N=14)\end{array}$ & $\begin{array}{c}\text { Nonsurvivors } \\
(N=18)\end{array}$ & $\begin{array}{c}p \\
\text { value }\end{array}$ \\
\hline Lactate $(\mathrm{mmol} / \mathrm{L})$ & $8.64 \pm 3.96$ & $5.89 \pm 3.19$ & $10.6 \pm 3.57$ & $<0.001$ & $8.29 \pm 2.49$ & $6.77 \pm 2.52$ & $9.47 \pm 1.75$ & 0.001 \\
\hline Creatinine (mg/dl) & $1.51 \pm 0.50$ & $1.24 \pm 0.36$ & $1.69 \pm 0.5$ & 0.0043 & $1.59 \pm 0.53$ & $1.33 \pm 0.13$ & $1.73 \pm 0.62$ & 0.05 \\
\hline $\operatorname{GFR}(\mathrm{ml} / \mathrm{min})$ & $49.26 \pm 20.20$ & $62.53 \pm 20.63$ & $40.61 \pm 14.74$ & 0.005 & $43.04 \pm 14.06$ & $51.56 \pm 13.05$ & $38.78 \pm 12.83$ & 0.03 \\
\hline Baseline LVEF (\%) & $32.19 \pm 7.32$ & $31.86 \pm 7.55$ & $32.35 \pm 6.93$ & 0.79 & $31.07 \pm 7.35$ & $34.45 \pm 5.02$ & $28.45 \pm 7.92$ & 0.02 \\
\hline $\begin{array}{l}\text { STEMI at } \\
\text { presentation, } n(\%)\end{array}$ & $35(53.8)$ & $19(65.5)$ & $16(44.4)$ & 0.13 & $16(50)$ & $10(71.4)$ & $6(33.3)$ & 0.07 \\
\hline $\begin{array}{l}\text { Prehospital } \\
\text { thrombolysis, } n \text { (\%) }\end{array}$ & $9(13.8)$ & $4(13.8)$ & $5(13.9)$ & 1 & $5(15.6)$ & $2(14.3)$ & $3(16.7)$ & 1 \\
\hline $\begin{array}{l}\text { Duration of ICU stay, } \\
\text { days }\end{array}$ & $9.11 \pm 7.23$ & $14.5 \pm 5.02$ & $2[1-6.75]$ & $<0.001$ & $11.25 \pm 7.34$ & $14.71 \pm 6.32$ & 8 [1-17] & 0.05 \\
\hline $\begin{array}{l}\text { Duration of hospital } \\
\text { stay, days }\end{array}$ & $9.97 \pm 8.07$ & $16.46 \pm 5.37$ & $2[1-6.75]$ & $<0.001$ & $11.50 \pm 7.54$ & $15.29 \pm 6.51$ & $8[1-17]$ & 0.02 \\
\hline \multicolumn{9}{|l|}{ Scores on admission } \\
\hline SAPS II & $79.83 \pm 7.83$ & $76.66 \pm 6.3$ & $82.39 \pm 8.08$ & 0.003 & $79.5 \pm 9.41$ & $75.14 \pm 10.36$ & $82.89 \pm 7.18$ & 0.02 \\
\hline SOFA & $11.57=$ & 11.07 & $11.97 \pm$ & 0.06 & 11.13 & 10.8 & 11.33 & 0.59 \\
\hline IABP & $3.59 \pm 1.44$ & $2.93 \pm 1.39$ & $4.11 \pm 1.26$ & 0.001 & $3.84 \pm 1.22$ & $3.36 \pm 1.28$ & $4.22 \pm 1.06$ & 0.04 \\
\hline APACHE II & $33.17 \pm 5.65$ & $30.41 \pm 5.34$ & $35.39 \pm 4.92$ & $<0.001$ & $34.84 \pm 4.06$ & $32.86 \pm 3.11$ & $36.39 \pm 4.1$ & 0.01 \\
\hline CardShock & $6.4 \pm 1.344$ & $5.66 \pm 1.29$ & $7 \pm 1.07$ & $<0.001$ & $6.56 \pm 1.08$ & $6.14 \pm 1.35$ & $6.9 \pm 0.68$ & 0.05 \\
\hline ENCOURAGE & $25.46 \pm 6.44$ & $21.72 \pm 6.6$ & $28.47 \pm 4.69$ & $<0.001$ & $27.63 \pm 4.77$ & $25.14 \pm 4.13$ & $29.56 \pm 4.41$ & 0.007 \\
\hline SAVE & $-5.88 \pm 4.94$ & $-3.23 \pm 4.35$ & $-7.97 \pm 4.39$ & $<0.001$ & $-7 \pm 3.61$ & $-4.29 \pm 1.82$ & $-9.11 \pm 3.23$ & $<0.001$ \\
\hline
\end{tabular}

BMI: body mass index; PAD: peripheral artery disease; COPD: chronic obstructive pulmonary disease; GFR: glomerular filtration rate; PCI: percutaneous coronary intervention; CABG: coronary artery bypass graft; VT: ventricular tachycardia; VF: ventricular fibrillation; CPR: cardiopulmonary resuscitation; ROSC: return of spontaneous circulation; LVEF: left ventricular ejection fraction; STEMI: ST-elevation myocardial infarction; ICU: intensive care unit; SAPS II: simplified acute physiology score II; SOFA: sequential organ failure assessment; IABP: intra-aortic balloon pump; APACHE: acute physiology and chronic health; ENCOURAGE: prediction of cardiogenic shock outcome for AMI patients salvaged by VA-ECMO; SAVE: survival after venoarterial extracorporeal membrane oxygenation (VA-ECMO). Numbers are presented as mean ( \pm standard deviation) or median (interquartile range, IQR $25^{\text {th }}-75^{\text {th }}$ percentile) or frequency (percentile).

SOFA, SAPS, IABP shock, CardShock, APACHE II, ENCOURAGE, and SAVE score was $70 \%, 85 \%, 55 \%, 80 \%, 85 \%$, $75 \%$, and $70 \%$, respectively. In our overall cohort, a total mortality rate of $55.2 \%$ was demonstrated, which represents a remarkable reduction according to the predicted mortality from the scores. The ENCOURAGE score appeared to be the most effective predictive model of mortality outcome in this setting of patients in both groups by reaching only a moderate AUC of 0.79 , followed by the CardShock, APACHE II, IABP, and SAPS score. These derived an AUC between 0.71 and 0.78 . The SOFA and the SAVE score did not appear to be effective predictors of the outcome in this particular setting of refractory CS after OHCA due to AMI. The predictive values of each score according to the groups are demonstrated in Figures 1 and 2.

\section{Discussion}

This analysis investigates, for the first time, solely patients supported with Impella in the particular setting of OHCA and postcardiac arrest CS complicating AMI in contrast to previous studies on mixed cohorts with and without previous cardiac arrest. To our knowledge, our analysis represents the largest single-center study to date concentrating on the use of Impella in OHCA patients with postcardiac arrest CS. The major finding of our study is the fact that the traditionally used prediction ICU and CS scores failed to offer a reliable prediction of outcome either in the setting of Impella 2.5 or CP LV unloading principle, while none of the scores reached an AUC of more than 0.8. On the contrary, it should be noted that the preimplantation cardiac arrest is a major determinant of CS mortality and that, in these patients, several factors quite rapidly influence 30 -day mortality, which cannot solely be attributed to CS. For example, the anoxic brain death occurs before admission and cannot be influenced by the restoration of the hemodynamic profile from devices, such as Impella. This makes the development of scores in this patient collective very challenging. In our cohort, the best predictive performance was offered by the ENCOURAGE score, which consists of a score initially designed for ECMO patients, reaching only a moderate AUC of 0.79 . Only few studies have questioned the predictive value of the most traditional and mostly used ICU and CS scores in patients treated with Impella for refractory CS. In the study by Sieweke et al., CardShock and IABP shock showed an acceptable predictive capacity among patients with CS [16]. However, in this study, only $60 \%$ of the participants were resuscitated prior to Impella implantation, and only $75 \%$ of the patients had CS due to an AMI. Moreover, all patients underwent an Impella CP implantation, which offers better and more effective unloading of the left ventricle accounting for better outcome. Under such perspectives, the assumption that these scores can effectively predict the outcome in OHCA with refractory CS due to a CS treated with Impella 2.5 remains premature. The study of all scores in this homogenous group of patients for both Impella devices is a major strength of our study. In another recent study of patients with CS due to an AMI, IABP score 
TABLE 2: Procedural characteristics of the overall cohort.

\begin{tabular}{|c|c|c|c|c|c|c|c|c|}
\hline & $\begin{array}{l}\text { All patients } \\
\quad(n=65)\end{array}$ & $\begin{array}{c}\text { Survivors } \\
(n=29)\end{array}$ & $\begin{array}{c}\text { Nonsurvivors } \\
\quad(n=36)\end{array}$ & $p$ value & $\begin{array}{c}\text { Impella CP } \\
(N=32)\end{array}$ & $\begin{array}{c}\text { Survivors } \\
(N=14)\end{array}$ & $\begin{array}{c}\text { Nonsurvivors } \\
\quad(N=18)\end{array}$ & $p$ value \\
\hline $\begin{array}{l}\text { Duration of } \\
\text { Impella } \\
\text { support } \\
\text { (hours) }\end{array}$ & $71[14-127.5]$ & $\begin{array}{c}118.5 \\
{[69.25-144]}\end{array}$ & $31[6.5-79.5]$ & 0.0003 & $78.77 \pm 52.53$ & $105 \pm 44.44$ & $48[12-88.5]$ & 0.04 \\
\hline $\begin{array}{l}\text { Door to } \\
\text { balloon }(\min )\end{array}$ & $85.21 \pm 39.47$ & $86.63 \pm 40.24$ & $83.90 \pm 39.4$ & 0.8 & $73[69-102]$ & $73[65-79]$ & $73[69-124]$ & 0.37 \\
\hline $\begin{array}{l}\text { Door to } \\
\text { Impella } \\
\text { support (min) }\end{array}$ & $105.5 \pm 53.48$ & $87 \pm 42.78$ & $120.9 \pm 57.18$ & 0.02 & $\begin{array}{c}72.5 \\
{[57.5-105]}\end{array}$ & $62.5[43-80]$ & $\begin{array}{c}102.5 \\
{[61-150.3]}\end{array}$ & 0.03 \\
\hline $\begin{array}{l}\text { Time from } \\
\text { ROSC to } \\
\text { hospital } \\
\text { admission } \\
\text { (min) }\end{array}$ & $75.98 \pm 36$ & $74.58 \pm 37.69$ & $77.06 \pm 35.23$ & 0.8 & $56.83 \pm 34.54$ & $57.44 \pm 24.90$ & $56.38 \pm 41.13$ & 0.93 \\
\hline $\begin{array}{l}\text { Number of } \\
\text { stents used* }\end{array}$ & $2[1-3]$ & $1.5[1-3]$ & $2[1-3]$ & 0.99 & $3[1-3.75]$ & $3[1-4]$ & $2[1-3]$ & 0.35 \\
\hline Culprit vessel, r & $n(\%)$ & & & & & & & \multirow{6}{*}{$\begin{array}{c}\text { NS for all } \\
\text { comparisons }\end{array}$} \\
\hline Left main & $3(4.6)$ & $1(3.4)$ & $2(5.6)$ & \multirow{5}{*}{$\begin{array}{c}\text { NS for all } \\
\text { comparisons }\end{array}$} & $2(6.3)$ & $2(14.3)$ & $0(0)$ & \\
\hline $\mathrm{LAD}$ & $35(53.8)$ & $17(58.6)$ & $18(50)$ & & $16(50)$ & $7(50)$ & $9(50)$ & \\
\hline $\mathrm{LCx}$ & $13(20)$ & $7(24.1)$ & $6(16.7)$ & & $5(15.6)$ & $2(14.3)$ & $3(16.7)$ & \\
\hline RCA & $12(18.5)$ & $4(13.9)$ & $8(22.2)$ & & $6(18.8)$ & $3(21.4)$ & $3(16.7)$ & \\
\hline Bypass graft & $2(3.1)$ & $0(0)$ & $2(5.5)$ & & $3(9.3)$ & $0(0)$ & $3(16.7)$ & \\
\hline \multicolumn{9}{|c|}{ Number of vessels diseased ${ }^{* *}$} \\
\hline 1 & $15(23.1)$ & $9(31)$ & $6(16.7)$ & \multirow{3}{*}{$\begin{array}{c}\text { NS for all } \\
\text { comparisons }\end{array}$} & $5(15.6)$ & $2(14.3)$ & $3(16.7)$ & \multirow{3}{*}{$\begin{array}{c}\text { NS for all } \\
\text { comparisons }\end{array}$} \\
\hline 2 & $20(30.8)$ & $8(27.6)$ & $12(33.3)$ & & $11(34.4)$ & $4(28.6)$ & $7(38.9)$ & \\
\hline 3 & $30(46.2)$ & $12(41.4)$ & $18(50)$ & & $16(50)$ & $8(57.1)$ & $8(44.4)$ & \\
\hline $\begin{array}{l}\text { Multivessel } \\
\text { intervention }\end{array}$ & $14(21.5)$ & $8(27.6)$ & $6(16.7)$ & 0.37 & $9(28.1)$ & $4(28.6)$ & $5(27.8)$ & 0.45 \\
\hline Successful PCI & $63(96.9)$ & $28(96.5)$ & $35(97.2)$ & 1 & $32(100)$ & $14(100)$ & $18(100)$ & 1 \\
\hline \multicolumn{9}{|c|}{ Use of GP IIb/IIIa receptor inhibitors } \\
\hline Tirofiban & $9(13.8)$ & $7(24.1)$ & $2(5.5)$ & NS for all & $6(18.8)$ & $4(28.6)$ & $2(11.1)$ & \multirow{2}{*}{$\begin{array}{c}\text { NS for all } \\
\text { comparisons }\end{array}$} \\
\hline Abciximab & $6(9.2)$ & $1(3.4)$ & $5(13.9)$ & comparisons & $3(9.4)$ & $3(21.4)$ & $0(0)$ & \\
\hline $\begin{array}{l}\text { Duration of } \\
\text { intervention } \\
(\mathrm{min})\end{array}$ & $119 \pm 47.01$ & $112.2 \pm 57.09$ & $124.5 \pm 37.07$ & 0.33 & $125.3 \pm 50.95$ & $128.0 \pm 68.05$ & $122.9 \pm 31.51$ & 0.79 \\
\hline $\begin{array}{l}\text { Contrast agent } \\
(\mathrm{ml})\end{array}$ & $289.4 \pm 122.4$ & $308.3 \pm 143.7$ & $273.8 \pm 101.6$ & 0.31 & $347 \pm 150$ & $375.7 \pm 173.9$ & $321.9 \pm 125.9$ & 0.34 \\
\hline
\end{tabular}

LAD: left anterior descending artery, LCx: left circumflex artery, RCA: right coronary artery, ROSC: return of spontaneous circulation, PCI: percutaneous coronary intervention; GP: glycoprotein. Numbers are presented as mean ( \pm standard deviation), median (interquartile range, IQR 25 th- 75 th percentile) or frequency (percentile). ${ }^{*}$ Only drug-eluting stents were used. ${ }^{* *}>50 \%$ stenosis in the nonculprit vessel.

presented to have achieved a good predictive capacity in patients treated with Impella (true $20 \%$ survival in the highrisk group and $48 \%$ in the low-intermediate group, whereas score-predicted mortality was $80 \%$ and $50 \%$ in these groups, respectively) [12]. In this study, only $61 \%$ of the patients were resuscitated prior to Impella initiation, and only $20 \%$ of the participants had suffered non-ST-elevation myocardial infarction (NSTEMI). In the same study, the SAPS II score offered, with a median value of 68 , an estimated mortality of almost $70 \%$, clearly overestimated as compared to the final survival of $48 \%$. Similarly, the SAPS II score overestimated the mortality in a group of 28 patients with profound CS treated with Impella CP (only 53.6\% due to AMI, estimated mortality $87 \%$, and true mortality $70 \%$ ) [11]. In a study with biventricular unloading, the addition of Impella on ECLS in patients with severe LV dysfunction led to an improvement of the expected survival (SOFA score 12, estimated mortality more than $80 \%$, and true survival $53 \%$ ); however, only $52 \%$ of the patients had CS due to an AMI [9]. In the study by Schiller et al., the SAVE score offered only a moderate predictive value in patients with CS treated with Impella with a referred AUC of less than 0.65 [19]. In our cohort, ENCOURAGE score, though produced as the predictor for the outcome in ECLS patients, was the best predictor of mortality. There are several possible explanations for this finding. In the IABP and CardShock score, the cutoff point for scoring age is 73 and 75 years of age, respectively. This age is often seen as a contraindication for a mechanical support in patients suffering an OHCA so that the implementation of these scores could lead to underestimation of the predicted mortality due to the lack of weighting according to age. In the ENCOURAGE score, the cutoff 
TABLe 3: Survival and safety outcomes.

\begin{tabular}{|c|c|c|c|c|c|c|c|c|}
\hline & $\begin{array}{l}\text { Impella } 2.5 \\
(n=65)\end{array}$ & $\begin{array}{l}\text { Survivors } \\
(n=29)\end{array}$ & $\begin{array}{c}\text { Nonsurvivors } \\
\quad(n=36)\end{array}$ & $\begin{array}{c}p \\
\text { value }\end{array}$ & $\begin{array}{l}\text { Impella CP } \\
\qquad(N=32)\end{array}$ & $\begin{array}{l}\text { Survivors } \\
(N=14)\end{array}$ & $\begin{array}{l}\text { Nonsurvivors } \\
\qquad(N=18)\end{array}$ & $\begin{array}{c}p \\
\text { value }\end{array}$ \\
\hline $\begin{array}{l}\text { Survival to hospital } \\
\text { discharge, } n(\%)\end{array}$ & $29(44.6)$ & $29(100)$ & - & - & $14(43.8)$ & $14(100)$ & - & - \\
\hline CPC $1-2, n(\%)$ & $22(75.9)$ & $22(75.9)$ & - & - & $11(78.6)$ & $11(78.6)$ & - & - \\
\hline CPC $3-4, n(\%)$ & $7(24.1)$ & $7(24.1)$ & - & - & $3(21.4)$ & $3(21.4)$ & - & - \\
\hline \multicolumn{9}{|l|}{ Causes of death } \\
\hline $\begin{array}{l}\text { Cardiogenic shock/MOF, } n \\
(\%)\end{array}$ & $33(50.8)$ & - & $33(91.7)$ & - & - & - & $15(83.3)$ & - \\
\hline Brain death, $n(\%)$ & $3(4.6)$ & - & $3(8.3)$ & - & - & - & $3(16.7)$ & - \\
\hline \multicolumn{9}{|l|}{ Complications } \\
\hline $\begin{array}{l}\text { Access-site bleeding } \\
\text { requiring transfusion, } n(\%)\end{array}$ & $6(9.2)$ & $3(10.3)$ & $3(8.3)$ & 1 & $7(21.9)$ & $3(21.4)$ & $4(22.2)$ & 1 \\
\hline $\begin{array}{l}\text { Limb ischemia requiring } \\
\text { extraction of the device, } n \\
(\%)\end{array}$ & $3(4.6)$ & $1(3.4)$ & $2(5.6)$ & 1 & $5(15.7)$ & $2(14.3)$ & $3(16.7)$ & 1 \\
\hline $\begin{array}{l}\text { Limb ischemia requiring } \\
\text { intervention, } n(\%)\end{array}$ & $2(3.1)$ & $1(3.4)$ & $1(2.8)$ & 1 & $4(12.5)$ & $2(14.3)$ & $2(11.1)$ & 1 \\
\hline $\begin{array}{l}\text { Pericardial effusion } \\
\text { needing paracentesis, } n(\%)\end{array}$ & $1(1.5)$ & $1(2.5)$ & $0(0)$ & 1 & $1(3.1)$ & $0(0)$ & $1(5.6)$ & 1 \\
\hline $\begin{array}{l}\text { Myocardial reinfarction, } n \\
(\%)\end{array}$ & $0(0)$ & $0(0)$ & $0(0)$ & 1 & $0(0)$ & $0(0)$ & $0(0)$ & 1 \\
\hline Stroke, $n(\%)$ & $0(0)$ & $0(0)$ & $0(0)$ & 1 & $1(3.1)$ & $0(0)$ & $1(5.6)$ & 1 \\
\hline $\begin{array}{l}\text { Nondevice-related } \\
\text { bleeding, } n(\%)\end{array}$ & $3(4.6)$ & $1(3.6)$ & $2(5.6)$ & 1 & $2(6.3)$ & $1(7.1)$ & $1(5.6)$ & 1 \\
\hline
\end{tabular}

CPC: cerebral performance category; MOF: multiorgan failure. Numbers are presented as frequencies (percentile).

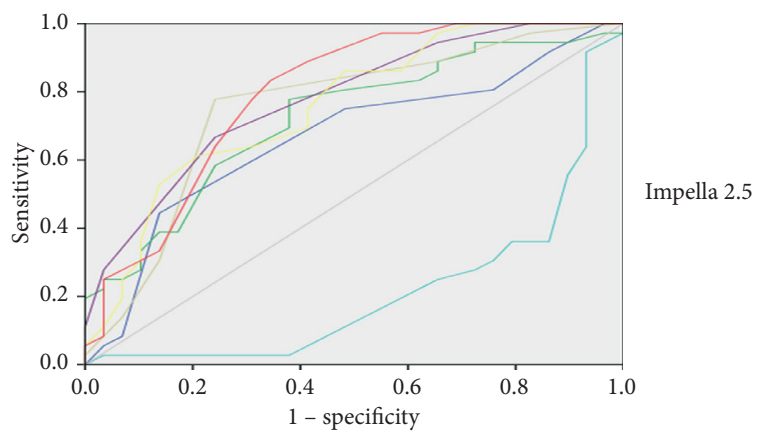

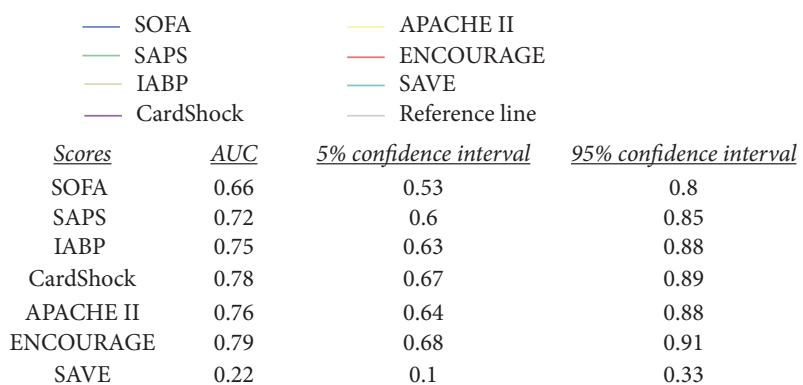

FIgURE 1: Comparison of the predictive values between the scores. Comparison of the sensitivity and specificity between different scores in patients supported with Impella 2.5. ENCOURAGE demonstrates the best area under the curve followed by CardShock, APACHE II, and IABP score. All scores demonstrate only a moderate prognostic accuracy; SAVE score cannot predict the outcome in this setting of patients.
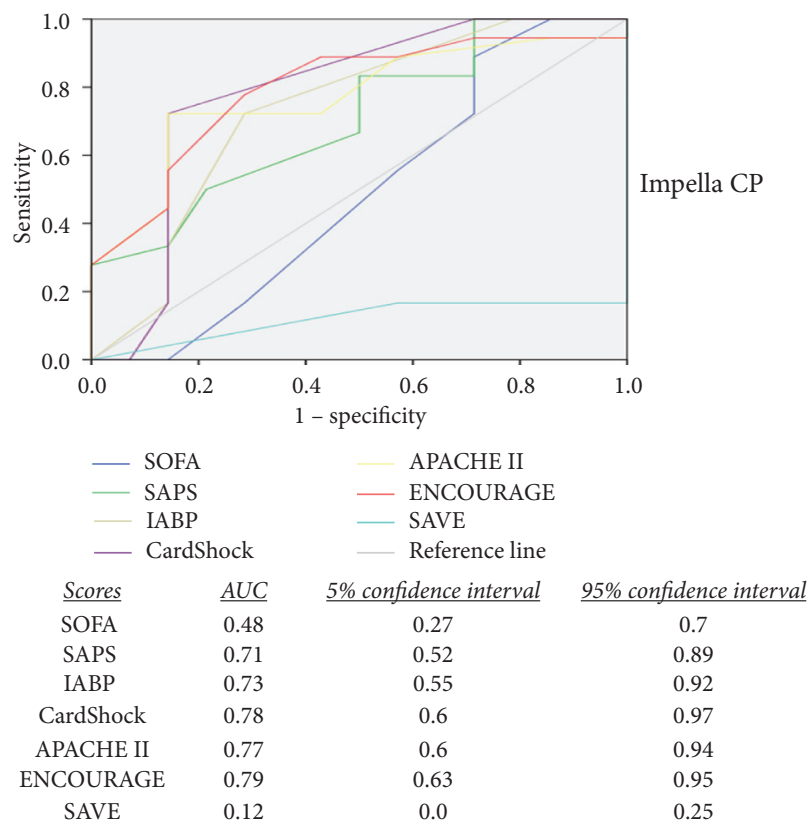

Figure 2: Comparison of the predictive values between the scores. Comparison of the sensitivity and specificity between different scores in patients supported with Impella CP. ENCOURAGE demonstrates the best area under the curve followed by CardShock, APACHE II, and IABP score. All scores demonstrate only a moderate prognostic accuracy; SAVE and SOFA scores cannot predict the outcome in these patients. 
value for age is 60 years. Moreover, the lactate values are the main contributor to the ENCOURAGE score: values $>8 \mathrm{mmol} / \mathrm{l}$ result in 11 points in this scoring system, while more than 28 points represent the high-risk group. In comparison, the CardShock and IABP scores only give a maximum of 2 (out of 9) points for the highest lactate levels (cutoff $>4 \mathrm{mmol} / \mathrm{l}$ and $>5 \mathrm{mmol} / \mathrm{l}$, respectively). However, the lactate levels are often very high in patients after successful CPR due to the dramatic and abrupt onset of diverse tissue hypoxia. The role of lactate as a determinant and predictor of outcome in patients after OHCA is undisputable $[20,21]$. On the contrary, lactate is not utilized in SAPS, SOFA, APACHE II, and SAVE score. These latter scores appear to be attractive scores for the prediction of mortality in ICU since they are based on a broad spectrum of laboratory measurements, which depict the organ function. However, in patients after OHCA, these parameters are often useless since they are rarely changed or minimally elevated upon admission or directly after the initiation of CPR. The SAVE score presented the worst prediction model in our cohort of patients. This could be attributed to the fact that the cause of OHCA was an AMI and also that initiation of support was mediated directly after admission so that two of the main contributors in this score were without any fluctuation in this group of patients.

We describe an overall hospital mortality of $55.7 \%$ (54/ 97). The cause of death was refractory CS/multiorgan failure in $49.5 \%$ (48 patients: 33 from the Impella 2.5 group and 15 from the Impella $\mathrm{CP}$ group) and anoxic brain damage in $6.2 \%$ (6/97, 3 patients in each group) of the total patients. In the particular setting of OHCA survivors with postcardiac arrest CS, Manzo-Silberman and colleagues, comparing Impella with IABP, reported a lower survival rate of $23 \%$ at 28 days in the Impella group (and $29.5 \%$ in the IABP group, $p=0.61$ ) [7]. On the contrary, our survival rates are concordant to previous real-world Impella cohorts, including a mixed population of patients with and without prior cardiac arrest [22-25]. Compared to the randomized IABP-SHOCK II and IMPRESS trials, our survival rates were rather lower. However, we consider our Impella cohort to be at a higher risk for in-hospital death than the Impella patients enrolled in previous registries and the aforementioned randomized studies since all our patients were resuscitated before Impella support and were being mechanically ventilated, having a higher prevalence of nonshockable first rhythm, which is a traditional risk factor for a worse outcome [26-29]. Additionally, NSTEMI was present as a cause for the OHCA CS in $47.4 \%$ of the patients in our cohort in contrast to the randomized IMPRESS trial, which included only STEMI patients reporting a mortality of $46 \%$ at 30 days and $50 \%$ at 6 months. However, CS complicating NSTEMI has significantly higher mortality than CS complicating STEMI [30]. Survival rates in realworld cohorts are often lower than in randomized controlled trials with MCS. Our registry describes the clinical usage of Impella 2.5 and CP in an unselected cohort of patients in postcardiac arrest CS with greater risk features than those reported in randomized trials, reflecting higher mortality observed in routine clinical practice in such patients.

\section{Study Limitations}

There are several limitations to consider for our study. Firstly, the retrospective nature of this study limits a definitive causal relationship between the time of Impella placement and the survival outcome. Timing of Impella initiation, extent of revascularization, and adjunctive therapies were left to the operator's discretion and, therefore, subject to selection and treatment biases. Secondly, we could only retrieve adverse events and complications that were properly documented in the patients' chart, and we were not able to present the whole range of complications according to initial scores, which could also be interesting. We, therefore, focused on mortality outcomes as the primary endpoint, which were well documented in our Impella registry. Lastly, the relative small sample size is another limitation. However, our goal was to correlate the initial calculated scores with the final outcome as well as to calculate the predictive value of these scores. This is thought to be a unique intention till today. Moreover, we believe that the homogeneity of our population with all patients receiving Impella for support in the setting of OHCA with CS complicating AMI after successful PCI as well as the separate analysis among the groups of Impella CP and 2.5 offers a fair and direct comparison between the scores.

\section{Conclusion}

Although the predictive value of the score to an individual clinical situation will always remain a challenge, such scoring systems might ease the communication of objective prognostic information to family members and surrogate decision makers, help ICU physicians to identify severe AMI patients with reasonable chance of survival, and reduce futile healthcare. The traditionally used and the newly developed scores in the field of CS offer only moderate prognostic information in patients with cardiogenic shock after OHCA treated with Impella. A new more potent score is needed in this setting in order to guide clinicians and interventional cardiologists to optimize the therapy in this group of patients.

\section{Data Availability}

The data used to support the findings of this study are available from the corresponding author upon reasonable request.

\section{Conflicts of Interest}

Drs. Schieffer, Karatolios, Markus, and Luesebrink have received speaker's honoraria from Abiomed. Drs. Chatzis, Syntila, Divchev, Ahrens, and Waechter declare no conflicts of interest. 


\section{References}

[1] E. J. Benjamin, M. J. Blaha, S. E. Chiuve et al., "Heart disease and stroke statistics-2017 update: a report from the American heart association," Circulation, vol. 135, no. 10, pp. e146-e603, 2017.

[2] S. Girotra, B. K. Nallamothu, J. A. Spertus, Y. Li, H. M. Krumholz, and P. S. Chan, "Trends in survival after inhospital cardiac arrest," New England Journal of Medicine, vol. 367, no. 20, pp. 1912-1920, 2012.

[3] J. Berdowski, R. A. Berg, J. G. P. Tijssen, and R. W. Koster, "Global incidences of out-of-hospital cardiac arrest and survival rates: systematic review of 67 prospective studies," Resuscitation, vol. 81, no. 11, pp. 1479-1487, 2010.

[4] J. S. Hochman, C. E. Buller, L. A. Sleeper et al., "Cardiogenic shock complicating acute myocardial infarction--etiologies, management and outcome: a report from the SHOCK trial registry should we emergently revascularize occluded coronaries for cardiogenic shock?" Journal of the American College of Cardiology, vol. 36, no. 3, pp. 1063-1070, 2000.

[5] H. Thiele, E. M. Ohman, S. de Waha-Thiele, U. Zeymer, and S. Desch, "Management of cardiogenic shock complicating myocardial infarction: an update 2019," European Heart Journal, vol. 40, no. 32, pp. 2671-2683, 2019.

[6] M. P. de Chambrun, N. Bréchot, G. Lebreton et al., "Venoarterial extracorporeal membrane oxygenation for refractory cardiogenic shock post-cardiac arrest," Intensive Care Medicine, vol. 42, no. 12, pp. 1999-2007, 2016.

[7] S. Manzo-Silberman, J. Fichet, A. Mathonnet et al., "Percutaneous left ventricular assistance in post cardiac arrest shock: comparison of intra aortic blood pump and IMPELLA recover LP2.5," Resuscitation, vol. 84, no. 5, pp. 609-615, 2013.

[8] K. Karatolios, G. Chatzis, B. Markus et al., "Impella support compared to medical treatment for post-cardiac arrest shock after out of hospital cardiac arrest," Resuscitation, vol. 126, pp. 104-110, 2018.

[9] S. Colombier, A. Quessard, C. Mastroianni et al., "Benefits of impella and peripheral veno-arterial extra corporeal life support alliance," ASAIO Journal, vol. 65, no. 8, pp. 837-844, 2019.

[10] P. Gaudard, M. Mourad, J. Eliet et al., "Management and outcome of patients supported with Impella 5.0 for refractory cardiogenic shock," Critical Care, vol. 19, p. 363, 2015.

[11] K. Lackermair, S. Sattler, B. C. Huber et al., "Retrospective analysis of circulatory support with the impella CP device in patients with therapy refractory cardiogenic shock," International Journal of Cardiology, vol. 219, pp. 200-203, 2016.

[12] B. Alushi, A. Douedari, G. Froehlig et al., "Impella versus IABP in acute myocardial infarction complicated by cardiogenic shock," Open Heart, vol. 6, no. 1, p. e000987, 2019.

[13] J. Pöss, J. Köster, G. Fuernau et al., "Risk stratification for patients in cardiogenic shock after acute myocardial infarction," Journal of the American College of Cardiology, vol. 69, no. 15, pp. 1913-1920, 2017.

[14] V.-P. Harjola, J. Lassus, A. Sionis et al., "Clinical picture and risk prediction of short-term mortality in cardiogenic shock," European Journal of Heart Failure, vol. 17, no. 5, pp. 501-509, 2015.

[15] M. Rivas-Lasarte, J. Sans-Rosello, E. Collado-Lledo et al., "External validation and comparison of the CardShock and IABP-SHOCK II risk scores in real-world cardiogenic shock patients," European Heart Journal: Acute Cardiovascular Care, Article ID 2048872619895230, 2020.
[16] J. T. Sieweke, D. Berliner, J. Tongers et al., "Mortality in patients with cardiogenic shock treated with the Impella CP microaxial pump for isolated left ventricular failure," European Heart Journal: Acute Cardiovascular Care, vol. 9, no. 2, pp. 138-148, 2020.

[17] G. Muller, E. Flecher, G. Lebreton et al., "The ENCOURAGE mortality risk score and analysis of long-term outcomes after VA-ECMO for acute myocardial infarction with cardiogenic shock," Intensive Care Medicine, vol. 42, no. 3, pp. 370-378, 2016.

[18] W. C. Chen, K. Y. Huang, C. W. Yao et al., "The modified SAVE score: predicting survival using urgent veno-arterial extracorporeal membrane oxygenation within 24 hours of arrival at the emergency department," Critical Care, vol. 20, no. 1, p. 336, 2016.

[19] P. Schiller, L. Hellgren, and P. Vikholm, "Survival after refractory cardiogenic shock is comparable in patients with impella and veno-arterial extracorporeal membrane oxygenation when adjusted for SAVE score," European Heart Journal: Acute Cardiovascular Care, vol. 8, no. 4, pp. 329-337, 2019.

[20] D. H. Lee, I. S. Cho, S. H. Lee et al., "Correlation between initial serum levels of lactate after return of spontaneous circulation and survival and neurological outcomes in patients who undergo therapeutic hypothermia after cardiac arrest," Resuscitation, vol. 88, pp. 143-149, 2015.

[21] C. Adrie, A. Cariou, B. Mourvillier et al., "Predicting survival with good neurological recovery at hospital admission after successful resuscitation of out-of-hospital cardiac arrest: the OHCA score," European Heart Journal, vol. 27, no. 23, pp. 2840-2845, 2006.

[22] A. Lauten, A. E. Engström, C. Jung et al., "Percutaneous leftventricular support with the impella-2.5-assist device in acute cardiogenic shock," Circulation: Heart Failure, vol. 6, no. 1, pp. 23-30, 2013.

[23] T. Loehn, W. W. O’Neill, B. Lange et al., "Long term survival after early unloading with Impella $\mathrm{CP}^{\circledast}$ in acute myocardial infarction complicated by cardiogenic shock," European Heart Journal: Acute Cardiovascular Care, vol. 9, no. 2, pp. 149-157, 2020.

[24] W. W. O’Neill, T. Schreiber, D. H. W. Wohns et al., "The current use of impella 2.5 in acute myocardial infarction complicated by cardiogenic shock: results from the USpella registry," Journal of Interventional Cardiology, vol. 27, no. 1, pp. 1-11, 2014.

[25] D. M. Ouweneel, J. de Brabander, M. Karami et al., "Real-life use of left ventricular circulatory support with Impella in cardiogenic shock after acute myocardial infarction: 12 years AMC experience," European Heart Journal: Acute Cardiovascular Care, vol. 8, no. 4, pp. 338-349, 2019.

[26] I. Wibrandt, K. Norsted, H. Schmidt et al., "Predictors for outcome among cardiac arrest patients: the importance of initial cardiac arrest rhythm versus time to return of spontaneous circulation, a retrospective cohort study," $B M C$ Emergency Medicine, vol. 15, no. 1, p. 3, 2015.

[27] L. Martinell, N. Nielsen, J. Herlitz et al., "Early predictors of poor outcome after out-of-hospital cardiac arrest," Critical Care, vol. 21, no. 1, p. 96, 2017.

[28] J. Herlitz, J. Engdahl, L. Svensson, K.-A. Ängquist, M. Young, and S. Holmberg, "Factors associated with an increased chance of survival among patients suffering from an out-of-hospital cardiac arrest in a national perspective in Sweden," American Heart Journal, vol. 149, no. 1, pp. 61-66, 2005. 
[29] M. Holmberg, S. Holmberg, and J. Herlitz, "Incidence, duration and survival of ventricular fibrillation in out-ofhospital cardiac arrest patients in Sweden," Resuscitation, vol. 44, no. 1, pp. 7-17, 2000.

[30] M. L. Anderson, E. D. Peterson, S. A. Peng et al., "Differences in the profile, treatment, and prognosis of patients with cardiogenic shock by myocardial infarction classification," Circulation: Cardiovascular Quality and Outcomes, vol. 6, no. 6, pp. 708-715, 2013. 